\title{
Proposal for a classification method of building materials in the Italian rules concerning low energy design
}

\author{
F. Cumo, L. Calcagnini \& G. Piras \\ Sapienza University of Rome, Italy
}

\begin{abstract}
In order to ensure that Italian building regulations comply with the Kyoto Protocol, we aim to propose a classification method for building materials. Actually, we aren't able to choose materials comparing their energy and environmental value. A database of building materials based on the LCA system is not yet available (national research "Genius loci"), but the rules about low energy building are mostly completed; we omit the rules and methods concerning how to choose materials in low energy buildings. Using a national LCA based database we aim to classify building materials into several classes and to define the possibility of choosing materials, balancing the environmental class and their weighting in the building. In this way we will provide the possibility for choosing materials based on their contribution to the environmental impact of the building as a whole. The idea is not to force designers, architects or engineers to choose all materials for a building which belong to the best class, but to force them to balance materials to guarantee that all of them together will produce a low environmental impact. To do this, each material has to be weighted on its LCA results and on its quantity. This method will agree with the spirit of the Italian law about low energy design and give to the designer the right flexibility in choosing materials, respecting a global environmental evaluation of building. It will also be a possible item for the implementation of the D. Lgs 192/05 that apply to EU Directive 2002/91/CE on the energy performance of buildings.
\end{abstract}

Keywords: building, material, legislation, policy, energy, LCA. 


\section{Introduction}

In August 2005 the Italian legislation, with the D. lgs 192/05, applied the Directive on the energy performance of buildings (2002/91/EC). The D. lgs $192 / 05$ regulate the design of low energy buildings establishing their energy performances (including envelope, systems, etc.), it defines methods and criteria to improve energy performance in buildings, to enhance development and integration of renewable sources and to achieve the national agreement of limiting greenhouse gas emission imposed under the Kyoto Protocol.

In order to respond to the Kyoto target (for the Italian Government it means a greenhouse gases emissions reduction of $6.5 \%$ for the 2012), and mainly to the limitation and/or reduction of gases emissions through recovery and use in waste management and in the production and to the promotion of forming databases to diffuse knowledge about climate changes and to control economic and social consequences of the different strategies, we have to consider the role of buildings material in terms of environmental impact and energy consumption. The goal is to create a national building material database and to classify building materials and components for their environmental and energy quality.

\section{Italian legislation and policy about Energy Performance of buildings}

In order to implement the previous legislation and with the target of a law linked to the economic policy, the D. lgs. 192/05 pursue the objective of qualifying buildings for their energy, environmental and economic sustainability. To achieve this goal this law previews a gradual application: law ties and burdens have different weight depending on the type of intervention (i.e. new construction, restoration, buildings dimension). This law, and its forthcoming actuative decree, aim to define the energy quality of buildings. The energy quality of buildings, that is the energy performance of all the parts that make a construction (envelope and systems), it's certified by an energy global certificate of the buildings; this document shows the measure of energy performance of a building on a range of values that represent a wide scale of buildings energy consumption. Because of the complexity of the various buildings, several classes are defined, more than the number indicated in the European guidelines; the range of the classes is subdivided from A to I, the high number of classes permit to show all the market possibility considering the average level of national buildings system, the difficulty of a complete knowledge of that system, and in order to encourage the passage from a class to an upper one and to avoid a too rigid and not improvable certification system.

The Italian law, just explained, regulate the main part of the energy used in the buildings sector, the one that will be used during the life of the buildings, but it does not consider the part of the energy embodied in the materials used to make constructions. The energy consumption to produce and transport building materials has to be considered in the energy performances of buildings (in 2000 the final energy consumption for buildings material in Italy was 5.269,1 tep [1]). 
The energy consumption of the production, transportation, maintenance, dismission and recycling of materials, otherwise all the consumption that come from the life cycle of materials are not "weighted" by law as a contribution in the rating of a building energy performances. Legislations need to be implemented with the building materials and components certification.

\section{Status quo about materials classification in EU}

In order to classify building materials, evaluating their energy performance end their environmental impact, the methodology is the one based on the Life Cycle Analysis. Through the LCA method it is possible, for each step, to evaluate the energy balance, the use of primary sources, the injurious air, ground and water emissions, the refusal and the condition of re-use and recycle materials. The LCA method makes possible a complete rating of a product and an interpretation of the data depending on what we are interested in (deciding the hierarchy of the impacts about energy consumption despite emissions or solid refusals). The "energy target" in the LCA is the reduction of source consumption, using recycle materials, low maintenance materials and/or long life materials.

Several European experiences about LCA and material archives can provide useful information for our study:

- Finland: in 2000 the Building Information Foundation RTS and the Finnish Society of Indoor Air Quality and Climate, aiming the use and development of low energy materials, codified an emission classification of building materials that has three emission classes, emission class M1 corresponds to the best quality and M3 lowest emission; in 2003 four Finnish research institutes designed a project to inform people regarding environmental impact and develop a tool called 'eco-benchmarks' for presenting LCAbased information and reliably the environmental impacts of consumption.

- UK: with The Environmental Profiles UK National Database, a "computer based tool providing LCA information for building materials, components and complete buildings based on data provided by UK manufacturers. The Database provides various levels of data ranging from per tonne inventory for individual materials to characterised and normalised data for over 200 building elements. The UK National Database from the Environmental Profiles of Construction Materials, Components and Buildings provides the user with the ability to compare the environmental profile of different materials and components using either functional units (e.g. $\mathrm{m}^{2}$ of building façade) or for some materials".

- Czech Republic: through the National Programme for Labelling Environmentally Friendly Products. This program consists in certification of product: selection of product lines-product categories, determine requirement file criteria, awarding of the Environmentally Friendly Product Ecolabel for products, which fulfil assigned criteria by license contract, implementation of verifications qualities of products in accordance with the setting out of ecological requirements and keeping license contract. 
- Switzerland: through a web based LCA database called Ecoinvent. This database was developed by the Swiss Centre for Life Cycle Inventories. The database accommodates more than 2500 background processes often required in LCA case studies. Quality guidelines, established in order to ensure coherent data acquisition and reporting across the various institutes involved, are described.

- Netherlands: by the year 2001 the Dutch government decided to implement sustainability requirements in the Dutch Building Decree, incorporating in the decree the material-based environmental performance profile of a building.

All this experience gives a picture, almost completely, of the European situation about the topic. There are completed database about industry products, such as for building components and product, there are web databases and ecolabelling voluntary certification. Anyhow, all these tools are not integrated in a Directive that could support the design processes and even the construction phases.

\section{The Italian situation}

Concerning building material certificate in terms of their environmental and energy quality the Italian legislation shows it is lacking. A "non update" experience of Based-LCA database that could be used to support and define the materials classification is the Italian database I-LCA by ANPA (2001), National Agency for the Environmental Protection; it was a primary database, not about components but raw materials (i.e. concretes, clay, etc.).

Actually, there is an "in progress" national research titled: "the role of buildings sector on climate changes: Genius Loci". "Genius Loci" is a national research that involves various bodies (from the Sapienza University of Rome, the University of Palermo, IPASS, CIRIAF to the ITC). One of the goals of this research is the collection of energy and environmental data of building materials, products and components, with the aim of giving a service to the sustainable policies regarding buildings processes and products, and mainly to the products certification in the buildings and design process.

This research will constitute the scientific support needed to define a complete Italian database and permit the implementation of the d.lgs. 192/05 and avoid all the choices about the right use of materials; it will be just voluntary acts of designers or industries.

Good data also allows industry to exercise a greater degree of control, or at least to argue a case to best effect, and it allows governments to assess and understand environmental issues and to then develop appropriate policy responses.

\section{Hypothesis of buildings materials classification and implementation of the existing law}

The Italian rules concerning low energy design (mostly forthcoming) measure the energy performance of buildings through and indicator of the building energy 
need, called EPi and expressed in $\mathrm{kWh} / \mathrm{m}^{2}$ anno; The Classes, as defined in a "still in progress" document, are from the A+ to the I. We aim to define a secondary energy performance indicator (sEPi), in order to complete the rating of the energy quality of the buildings.

This secondary indicator (sEPi) is to be assessed using, for example, the Life Cycle Assessment (LCA) method and it is to be applied in addition to other requirements, such as the energy performance coefficient (EPi) that is already included in the Italian rules and reflects the global energy efficiency. The process for the definition of the sEPi is the following:

1. Establish quantity of the main building materials and/or components used in the buildings (e.g. $\mathrm{m}^{2}$ of glass, $\mathrm{m}^{2}$ of wood pavement, $\mathrm{kg}$ of concrete etc.)

2. Quantify the embodied energy of each material by its energy consumption through based - LCA Database expressed in MJ. e.g. a unit $\left(1 \mathrm{~kg}\right.$ or $\left.1 \mathrm{~m}^{2}\right)$ of multilayers glass uses 2,7 MJ of energy to be product (from mineral and fossil fonts [2]). It means a total of $81 \mathrm{MJ}$.

3. These values are then summed-up to derive an overall material energy performance score for that element in terms of the energy performance profile involving the summation of the energy consumption of all elements. This yields a material-based energy performance indicator (sEPi).

We hope that the development of the sEPi indicator will make it possible for designers and researchers to assess completely the energy quality of building designs and material choices at an early stage in the project delivery process, to avoid the interpretation of too complex energy and environmental data, but to provide a tool to evaluate easily the design decisions. This final outcome is to be used to be applied together with the other energy not voluntary indicators as a secondary indicator establish by law.

In order to complete the Italian rules about energy performance building the secondary indicator (sEPi) should:

- individuate a range of classes for the material energy consumptions, from 1 to $\mathrm{x}$, not to be confused with the EPi classes;

- be applied gradually for the type of intervention. That means in case of new construction the minimum classes has to be e.g. the third one, in case of restoration the forth one. The calculation in case of small buildings such us $<1000 \mathrm{~m}^{2}$ has to be voluntary;

- be applied gradually in time. The limit established for the 2008 has increase for the 2010 buildings (e.g. the MJ of energy consumption of a building could result above the sEPi standard limit for the 2008 and under it for the 2010), in order to permit a lower energy consumption standard going on with time and with the international requirements;

- be represented through a benchmark rule that will be associated to the graphic representation of the EPi (forthcoming) and that will give to the people the idea of the energy quality of the material and add a new economical parameter for rating buildings on the market.

The following scheme will show how the indicator could be related to the existing law (see Figure 1). 
Based-LCA Database of Building

Materials, Components and Product

Step 1: Quantify building materials/ components (m2, kg, etc.)

Step 2: Quantify embodied energy of materials through based - LCA Database

Step 3: Summ values to derive an overall material energy performance score

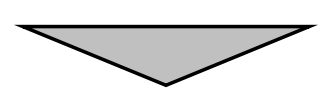

Hypothesis for the secondary energy performance indicator Classe [MJ]
Existing legislation: D.lgs. 192/05

E.g. Limit Value, from 2008 , for the index of energy performance. Buidings - Surface/Volume $=0,62$

Classes $[\mathrm{kWh} / \mathrm{m} 2$ year $]$

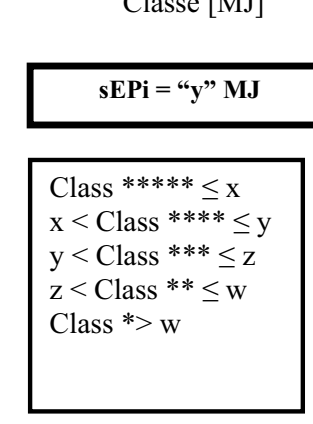

$\mathrm{EPi}=76 \mathrm{kWh} / \mathrm{m} 2$ year

\section{Class $\mathrm{A}+\leq 26$}

$26<$ Class A $\leq 45,5$

$45,5<$ Class B $\leq 65$

$65<$ Class $\mathrm{C} \leq 73$

$73<$ Class D $\leq 80$

$80<$ Class $\mathrm{E} \leq 96$

$96<$ Class $\mathrm{F} \leq 112$

$112<$ Class $\mathrm{G} \leq 136$

$136<$ Class $\mathrm{H} \leq 160$

Class I $>160$

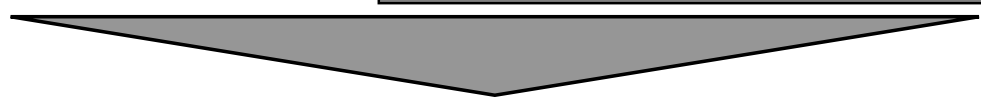

\section{Energy certificated building as} Class $D^{* * *}$

Figure 1.

\section{Conclusions and further development}

The further development will be the analysis of several buildings in order to establish the range of classes for the sEPi, to define the LCA data we require and to weight the materials embodied energy consumption compared with the energy performance of buildings measured by the EPi.

Furthermore, it is important to achieve the latest news about materials behaviour and labelling in all the European and North America Countries in order to develop a method that will be integrated with the highest technologies in the buildings sector.

\section{References}

[1] Ministero dello sviluppo economico. http:/www.sviluppoeconomico.gov. it/

[2] De Santoli L., Analisi del ciclo di vita del sistema edificio-impianto, ed. Palombi Editori, pg. 80-84, 2006 